\title{
Bilateral giant and unilateral duplicated sphenoidal tubercle
}

\author{
M.C. Rusu, R.C. Ciuluvică, A.D. Vrapciu, A.L. Chiriță, M. Predoiu, N. Măru \\ Division of Anatomy, Faculty of Dental Medicine, "Carol Davila" University of Medicine and Pharmacy, Bucharest, Romania
}

[Received: 15 January 2019; Accepted: 12 February 2019]

The sphenoidal tubercle (SphT), also known as pyramidal tubercle or infratemporal spine projects from the anterior end of the infratemporal crest of the greater sphenoidal wing. As it masquerades the lateral entrance in the pterygopalatine fossa it could obstruct surgical corridors or the access for anaesthetic punctures. The SphT is, however, an overlooked structure in the anatomical literature. During a routine cone beam computed tomography study in an adult male patient we found bilateral giant SphTs transforming the infratemporal surfaces of the greater wing into veritable pterygoid foveae. Moreover, on one side the SphT appeared bifid, with a main giant partition, of $9.17 \mathrm{~mm}$ vertical length, and a secondary laminar one. The opposite SphT had $14.80 \mathrm{~mm}$. In our knowledge, such giant and bifid SphTs were not reported previously and are major obstacles if surgical access towards the pterygopalatine fossa and the skull base is intended. (Folia Morphol 2019; 78, 4: 893-897)

Key words: greater wing of the sphenoid bone, pterygopalatine fossa, cone beam computed tomography, infratemporal fossa, maxillary nerve

\section{INTRODUCTION}

The sphenoidal tubercle (SphT) or infratemporal spine is a bony prominence located at the anterior end of the infratemporal crest of the greater sphenoidal wing [3], which is different of the sphenoidal spine located posteriorly [20]. The SphT was also described as a retroorbital "pyramidal process" and was observed to have three surfaces, anterior, posterior and lateral [7]. However, several morphologies of the SphT were described in a dry bones study: pyramidal, truncated pyramidal, smooth laminar, spiniform laminar and irregular laminar [3]. The spiniform type was the most frequent in a lot of 304 skulls [1]. To our knowledge there were not reported neither bifid and nor giant SphTs. When PubMed and Google Academic databases were searched for the terms "giant sphenoidal tubercle", "bifid sphenoidal tubercle" nothing was returned.
The infratemporal crest separates the temporal and infratemporal surfaces of the greater wing and attaches either fibres of temporal muscle or the lateral pterygoid muscle [18]. The respective deep portion of the temporal muscle was either indicated as sphenomandibular fascicle [3], or it was described as an individual structure, the sphenomandibular muscle, distinct from the overlying temporalis muscle [8]. This muscle fascicle could compress the maxillary nerve to trigger orofacial pain [3]. The inconstant pterygoideus proprius muscle of Henle could also originate from the infratemporal crest to insert either on the tuber palati, or on the lateral pterygoid plate [24]. Nevertheless, a distinctive sphenotemporalis muscle was identified attached to the SphT and the articular tubercle of the temporal bone [16, 24].

The SphT could appear isolated from the infratemporal crest, which is different of the classical textbooks definition [3]. 


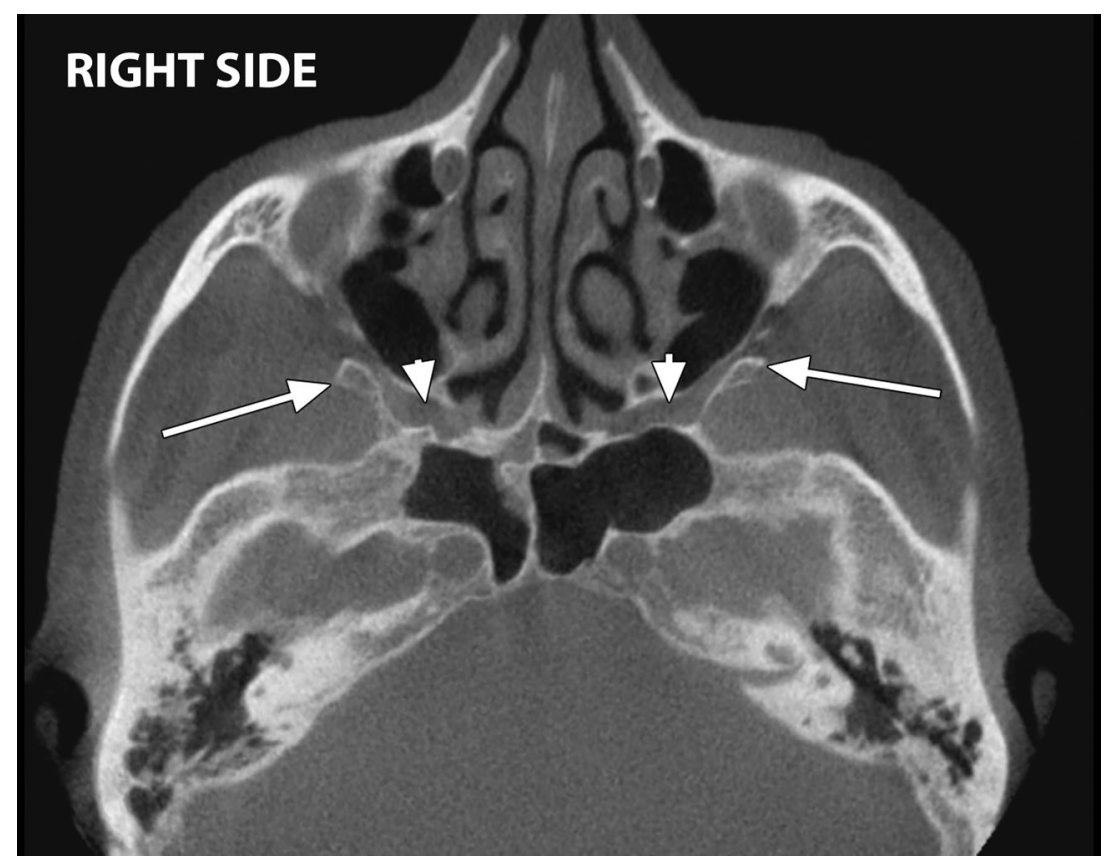

Figure 1. Axial multiplanar reconstructions in which there are observed bilateral sphenoidal tubercles (arrows) obstructing the entrances in the pterygopalatine fossae (arrowheads).

Nevertheless, the terms "sphenoidal tubercle" or "infratemporal spine" or "pyramidal process" do not appear mentioned in Bergman's Comprehensive Encyclopedia of Human Anatomic Variation [24].

We hereby report a rare anatomic variation, that of giant and bifid SphT, which, to our knowledge, was not reported previously.

\section{MATERIALS AND METHODS}

A retrospective study of the archived files of a 54-year-old male patient was performed. The subject was scanned for dental medical purpose using a cone beam computed tomography (CBCT) machine - iCat (Imaging Sciences International), the scanning protocol being: resolution 0.250 , field of view 130 , image matrix size $640 \times 640$, sensor dimension $20 \times 25 \mathrm{~cm}$; grayscale resolution $-14 \mathrm{bit}$; voxel dimension $-0.250 \mathrm{~mm}$; acquisition time $-13.9 \mathrm{~s}$; $120 \mathrm{kV}, 5 \mathrm{~mA}$; number of acquired images - 528, as previously described $[19,21]$. The patient was positioned according to the manufacturer's instructions. $\mathrm{CBCT}$ data was analysed using the iCatVision software and the application 3DVR v5.0.0.3, for the three-dimensional renderisations. We used bidimensional multiplanar reconstructions (MPRs) in the axial, coronal, sagittal or oblique planes, and three-dimensional volume renderisations (3DVRs) with variable filters and bone subtraction. The patient has given written informed consent for all medical data, including CBCT scans, to be used for research and teaching purposes, provided the protection of the identity is maintained.

\section{Anatomic variation}

On axial MPRs were observed bilaterally SphTs which were located posteriorly to the maxillary sinuses and were obstructing the upper segments of the pterygomaxillary fissures, thus the entrances to the pterygopalatine fossae (Fig. 1). The left SphT appeared bifid on 3DVRs, with a main postero-lateral larger component and a second antero-medial spiniform laminar component built-up from two discrete spines (Fig. 2). The SphTs were measured on coronal MPRs (Fig. 3): the main component of the left bifid one had a vertical length of $9.17 \mathrm{~mm}$ while the right SphT had $14.80 \mathrm{~mm}$.

The main left SphT and, respectively, the right SphT, appeared on 3DVRs as anterior bony shields (Figs. 2, 4) turning the infratemporal surfaces of each greater wing into veritable foveae for the origin of the upper heads of the lateral pterygoid muscles. On the left side that resulted infratemporal fovea of the greater wing was deeper, as also was the pterygoid fovea of the left mandible neck (Fig. 2). On the right side these were attenuated (Fig. 4). 


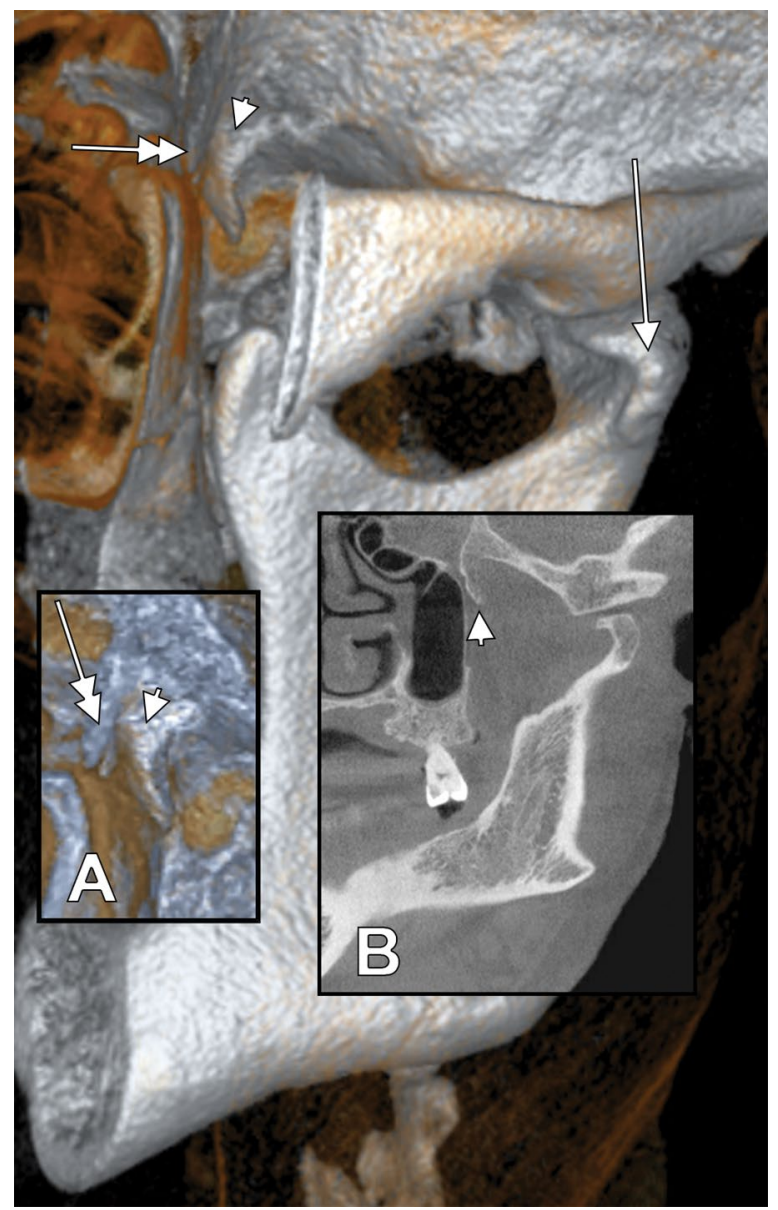

Figure 2. Three-dimensional volume renderisation. Left bifid sphenoidal tubercle, detailed in inset (A), consists of an anterior part with irregular free end consisting of two spines (double-headed arrow) and a posterior larger part (arrowhead) which, in turn, shields the situs of origin for the superior head of the lateral pterygoid muscle. A second such osseous shield (arrow) borders the pterygoid fovea on the mandible neck (detail on oblique/sagittal multiplanar reconstructions, in inset $[\mathbf{B}])$.

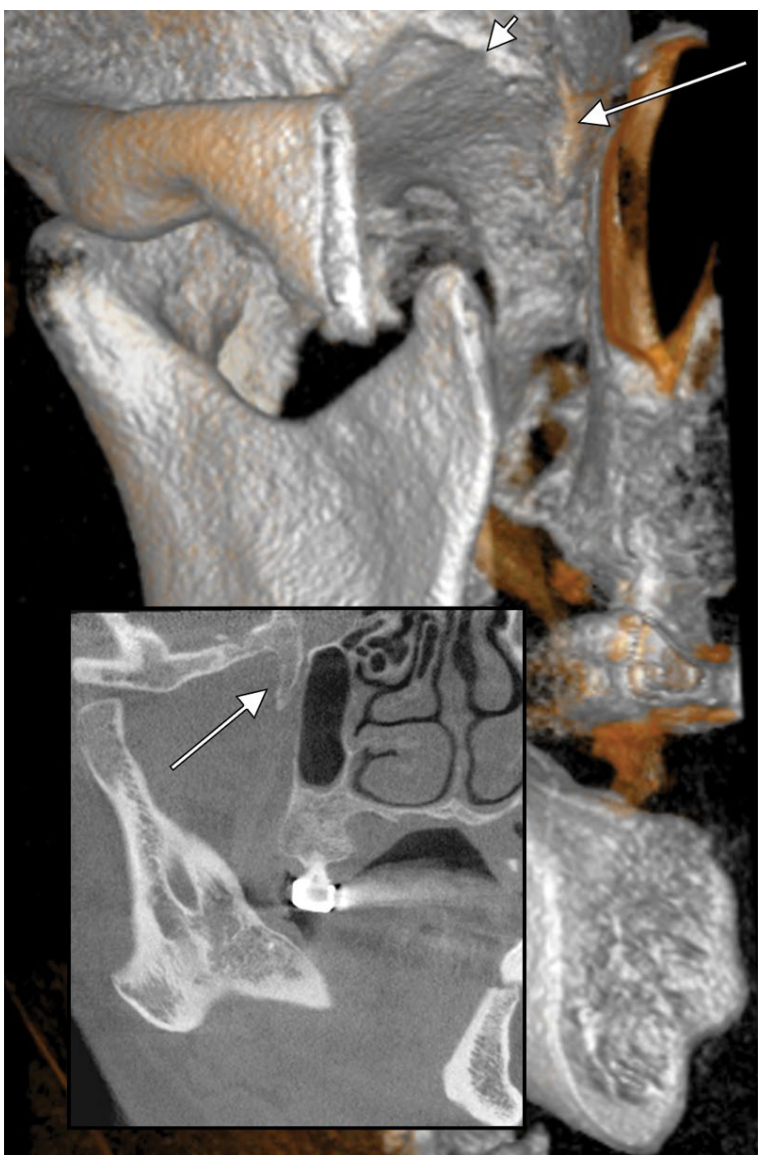

Figure 4. Three-dimensional volume renderisation. Right giant sphenoidal tubercle (arrow), also depicted on oblique/sagittal multiplanar reconstructions (inset). The arrowhead indicates the infratemporal crest of the greater sphenoidal wing.

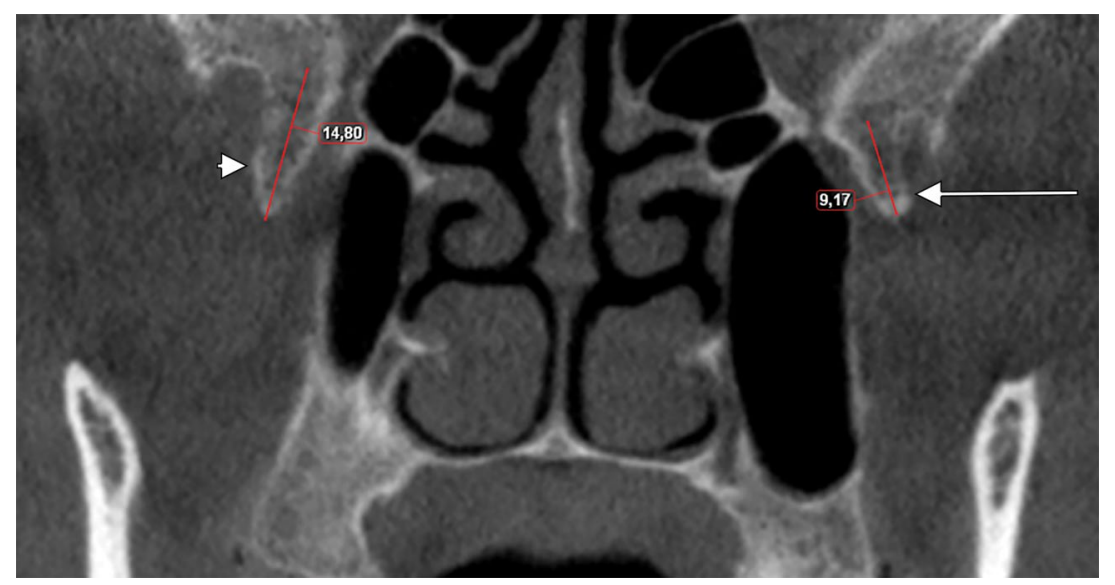

Figure 3. Coronal multiplanar reconstructions with vertical measurements of the right sphenoidal tubercle (arrowhead) and the posterior component of the left bifid sphenoidal tubercle (arrow). 


\section{DISCUSSION}

The anatomy of the temporal, infratemporal and pterygopalatine fossae are of great interest for a variety of specialties such as neurosurgery, otolaryngology, maxillofacial surgery, and facial reconstructive surgery.

The mean vertical size of the SphT was found in $98.4 \%$ of 60 dry skulls, being bilateral in $76.6 \%$ of those cases; its average vertical diameter was of $3.89 \mathrm{~mm}$ [18]. As the SphTs we found had more than twice that average vertical size (the main left SphT: $9.17 \mathrm{~mm}$ and the right SphT: $14.80 \mathrm{~mm}$ ) they could be considered as "giant" SphTs.

Maxillary nerve block in the pterygopalatine fossa could be performed either by intraoral, or by extraoral techniques $[17,23]$. While the former would not interfere with a giant sphenoidal tubercle, an obstacle obstructing the pterygomaxillary fissure, such as is a giant SphT, should be documented prior to extraoral techniques (e.g. the sigmoid or frontozygomatic approaches), to avoid failures.

The endonasal endoscopic surgery provides access to a considerable skull base surface, from the frontal sinus to the foramen magnum and the axis $[4,12$, $13,22]$. While performing maxillary antrostomy for the endoscopic approach to the middle cranial fossa, the superomedial part of the pterygopalatine fossa is exposed [14]. By targeting the lateral wall of the cavernous sinus, the surgeon displaces laterally the content of the pterygopalatine fossa [14], thus the presence of the SphT must be well documented, in order to preserve the anatomic structures of this space.

During the separation of the maxilla from the pterygomaxillary junction, performed in maxillary osteotomy required for rectification of dentofacial and craniofacial malformations [6], it is mandatory an adequate knowledge of the relationship between the maxillary artery and the pterygomaxillary fissure. In such procedure, the bleeding of the main trunk or branches of the maxillary artery is a serious surgical complication $[2,15]$, especially in the circumstances of a reduced pterygomaxillary fissure decreased by the presence of a giant SphT. Such a giant SphT could also represent an obstacle during the lateral surgical approach of the pterygopalatine fossa.

The superior head of the lateral pterygoid muscle originates from the upper third of the lateral pterygoid plate, the infratemporal surface of the greater wing of the sphenoid bone medial to the infratemporal crest and lateral to foramen ovale [5]. It is therefore directly related to the SphT and the resulted bony shield which determined the infratemporal fovea of the greater wing. It was assessed that neither age nor the state of the dentition seems to interfere with the architecture of the lateral pterygoid muscle [11], being therefore reasonable to consider that the peculiar osseous anatomy of the greater wing is not related to a functional status of that muscle.

In Gray's Anatomy (20 th edition) the SphT is described as a triangular process that increases the attachment of the lateral pterygoid muscle and is located medial to the anterior extremity of the infratemporal crest [9]. The description was kept in the $37^{\text {th }}$ edition of Gray's Anatomy [25], but in the $41^{\text {st }}$ edition of the respective textbook this bony process was overlooked [10].

\section{CONCLUSIONS}

In conclusion, we strongly adhere to the suggestion that the SphT should be incorporated into international anatomical terminology with the term "sphenoidal tuberculum" [1] and we recommend the morphological possibilities of bifidity and giant shape to be considered as anatomical variants.

\section{REFERENCES}

1. Alves N, Deana NF. Morphological study of the tuberculum sphenoidalis in macerated skulls of adult individuals. Folia Morphol. 2015; 74(4): 465-469, doi: 10.5603/ FM.2015.0108, indexed in Pubmed: 26620506.

2. Apinhasmit W, Methathrathip D, Ploytubtim S, et al. Anatomical study of the maxillary artery at the pterygomaxillary fissure in a Thai population: its relationship to maxillary osteotomy. J Med Assoc Thai. 2004; 87(10): 1212-1217, indexed in Pubmed: 15560700.

3. Cáceres F, Pedemonte M, Cerda V, et al. Frequency and characterization of the infratemporal spine in a sample of chilean human skulls. Int J Morphol. 2016; 34(4): 1414-1418, doi: 10.4067/s0717-95022016000400039.

4. Cappabianca P, Cavallo LM, Esposito F, et al. Extended endoscopic endonasal approach to the midline skull base: the evolving role of transsphenoidal surgery. Adv Tech Stand Neurosurg. 2008; 33: 151-199, indexed in Pubmed: 18383814.

5. Carpentier P, Yung JP, Marguelles-Bonnet R, et al. Insertions of the lateral pterygoid muscle: an anatomic study of the human temporomandibular joint. J Oral Maxillofac Surg. 1988; 46(6): 477-482, doi: 10.1016/0278-2391(88)90417-x, indexed in Pubmed: 3164053.

6. Choi J, Park HS. The clinical anatomy of the maxillary artery in the pterygopalatine fossa. J Oral Maxillofac Surg. 2003; 61(1): 72-78, doi: 10.1053/joms.2003.50012, indexed in Pubmed: 12524612.

7. Dunn G, Hack G, Robinson W, et al. Anatomical observation of a craniomandibular muscle originating from the 
skull base: the sphenomandibularis. CRANIO. 1996; 14: 97-105, doi: 10.1080/08869634.1996.11745955.

8. Geers C, Nyssen-Behets C, Cosnard G, et al. The deep belly of the temporalis muscle: an anatomical, histological and MRI study. Surg Radiol Anat. 2005; 27(3): 184-191, doi: 10.1007/s00276-004-0306-3, indexed in Pubmed: 15821860.

9. Gray H. Anatomy of the human body. 20th ed. Lea \& Febiger, Philadelphia 1918.

10. Gray H, Standring S, Anand N, Birch R, Collins P, Crossman A Gleeson $M$, Jawaheer G, Smith AL, Spratt JD, Stringer MD, Tubbs SR, Tunstall R, Wein AJ, Wigley CB. Gray's anatomy: The anatomical basis of clinical practice. $41 \mathrm{ed}$. Elsevier 2016.

11. Haddioui A, Laison F, Zouaoui A, et al. Functional anatomy of the human lateral pterygoid muscle. Surg Radiol Anat. 2005; 27(4): 271-286, doi: 10.1007/s00276-005-0324-9, indexed in Pubmed: 16200387.

12. Kassam A, Snyderman $\mathrm{CH}$, Mintz A, et al. Expanded endonasal approach: the rostrocaudal axis. Part I. Crista galli to the sella turcica. Neurosurg Focus. 2005; 19(1): E3, indexed in Pubmed: 16078817.

13. Kassam A, Snyderman CH, Mintz A, et al. Expanded endonasal approach: the rostrocaudal axis. Part II. Posterior clinoids to the foramen magnum. Neurosurg Focus. 2005; 19(1): E4, indexed in Pubmed: 16078818.

14. Komatsu F, Oda S, Shimoda M, et al. Endoscopic endonasal approach to the middle cranial fossa through the cavernous sinus triangles: anatomical considerations. Neurol Med Chir (Tokyo). 2014; 54 Suppl 3(12): 1004-1008, indexed in Pubmed: 26236810.

15. Lanigan DT, Hey JH, West RA. Major vascular complications of orthognathic surgery: hemorrhage associated with Le Fort I osteotomies. J Oral Maxillofac Surg. 1990; 48(6): 561-573, doi: 10.1016/s0278-2391(10)80468-9, indexed in Pubmed: 2341936.

16. Mack PJ. Sphenotemporalis: a new muscle in man. J Anat. 1984; 139 (Pt 4): 587-591, indexed in Pubmed: 6526712.
17. Radder K, Shah A, Kothari C, et al. Comparison of Frontozygomatic versus Sigmoid Notch Approach for Extraoral Maxillary Nerve Block Anesthesia: A Prospective Clinical Trial. J Maxillofac Oral Surg. 2018; 17(3): 301-307, doi: 10.1007/s12663-017-1045-4, indexed in Pubmed: 30034148.

18. Ramos VV, Robles PF. Morphological and morphometric characterization of the "sphenoidal tubercle". Int J Morphol. 2018; 36.

19. Rusu MC, Didilescu AC, Jianu AM, et al. 3D CBCT anatomy of the pterygopalatine fossa. Surg Radiol Anat. 2013; 35(2): 143-159, doi: 10.1007/s00276-012-1009-9, indexed in Pubmed: 22918475.

20. Rusu MC, Leonardi R. The sphenoidal spine and the sphenoidal tubercle. Int J Oral Maxillofac Surg. 2010; 39(10): 1042-1043, doi: 10.1016/j.ijom.2010.06.008, indexed in Pubmed: 20599353.

21. Rusu MC, Săndulescu M, Bichir $C$, et al. Combined anatomical variations: The mylohyoid bridge, retromolar canal and accessory palatine canals branched from the canalis sinuosus. Ann Anat. 2017; 214: 75-79, doi: 10.1016/j. aanat.2017.07.006, indexed in Pubmed: 28823708.

22. Shin M, Kondo K, Saito N. Neuroendoscopic transnasal surgery for skull base tumors: basic approaches, avoidance of pitfalls, and recent innovations. Neurol Med Chir (Tokyo). 2012; 52(10): 697-703, doi: 10.2176/nmc.52.697, indexed in Pubmed: 23095261.

23. Thangavelu K, Kumar NS, Kannan R, et al. Maxillary nerve block in management of maxillary bone fractures: Our experience. Anesth Essays Res. 2012; 6(1): 58-61, doi: 10.4103/0259-1162.103376, indexed in Pubmed: 25885504.

24. Tubbs RS, Loukas M, Shoja MM. Bergman's comprehensive encyclopedia of human anatomic variation. John Wiley \& Sons, Hoboken, NJ 2016.

25. Williams PL, Warwick R, Dyson M, Bannister LH. Gray's anatomy. 37th ed. Churchill Livingstone, Edinburgh 1989. 
